\title{
Rancang Bangun Aplikasi Buku Saku Badan Pusat Statistik Kabupaten Garut
}

\author{
Muhammad Rikza Nashrulloh \\ Jurnal Algoritma \\ Sekolah Tinggi Teknologi Garut \\ J1. Mayor Syamsu No. 1 Jayaraga Garut 44151 Indonesia \\ Email : jurnal@sttgarut.ac.id \\ rikza@itg.ac.id
}

\begin{abstract}
Abstrak-E-Government adalah cara pemerintah menggunakan teknologi informasi yang inovatif untuk meningkatkan kualitas layanan, salah satunya menggunakan teknologi smartphone berbasis android. Android merupakan sistem informasi yang paling sering diakses oleh pengguna. Badan Pusat Statistik merupakan lembaga pemerintahan yang bertanggung jawab langsung kepada Presiden. Permasalahan yang terjadi bahwa staff Badan Pusat Statistik Kabupaten Garut biasanya dibekali dengan buku saku BPS namun hanya disimpan saja. Aplikasi buku saku ini dibuat untuk memberikan alternatif penyajian informasi agar staff dapat mengakses buku saku kapan saja. Dalam pembuatan aplikasi metodologi yang digunakan adalah metodologi Agile Scrum. Aplikasi buku saku ini memiliki fitur profil BPS, jadwal kegiatan, master file desa se-Kabupaten Garut, indikator srategis, peta GIS Kabupaten Garut.
\end{abstract}

Kata Kunci-Agile Scrum; Android; Badan Pusat Statistik; E-Government.

\section{PENDAHULUAN}

Perkembangan teknologi pada era globalisasi saat ini berubah secara signifikan, bahkan teknologi menjadi kebutuhan yang sangat penting bagi sebuah organisasi [1]. Salah satu perkembangan teknologi yaitu teknologi smartphone. Android merupakan sistem operasi smartphone dengan $85 \%$ pengguna yang paling populer di dunia. Penggunaan teknologi sudah merambah ke seluruh institusi, baik swasta maupun pemerintahan. Dalam bidang pemerintahan teknologi ini lebih di kenal dengan istilah E-Government (Elektronik Government) [2].

E-Government adalah cara pemerintah dalam menggunakan teknologi informasi dan komunikasi yang paling inovatif, khususnya aplikasi berbasis android, dalam meningkatkan kualitas layanan pemerintahan salah satunya aplikasi buku saku [3]. Badan Pusat Statistik Kabupaten Garut adalah Lembaga Pemerintah NonDepartemen yang bertanggung jawab langsung kepada Presiden. Staf BPS biasanya dibekali dengan buku saku , tetapi jarang digunakan karena buku saku tersebut sering tertinggal. [4].

Berdasarkan permasalahan tersebut, maka perlu aplikasi buku saku Badan Pusat Statistik Kabupaten Garut berbasis android. Aplikasi ini dilengkapi jadwal kegiatan, master file desa se-Kabupaten Garut, indikator srategis, peta GIS Kabupaten Garut. Aplikasi ini diharapkan dapat bermanfaat bagi para staf BPS khususnya Kabupaten Garut.

\section{METODOLOGI PENELITIAN}

Metodologi penelitian yang digunakan oleh penulis dalam rancang bangun aplikasi buku saku Badan Pusat Statistik Kabupaten Garut ini antara lain adalah metode wawancara, observasi, studi literatur, pengembangan sistem dan pengujian sistem. Penjelasan lebih rinci dapat dilihat dalam diagram berikut. 


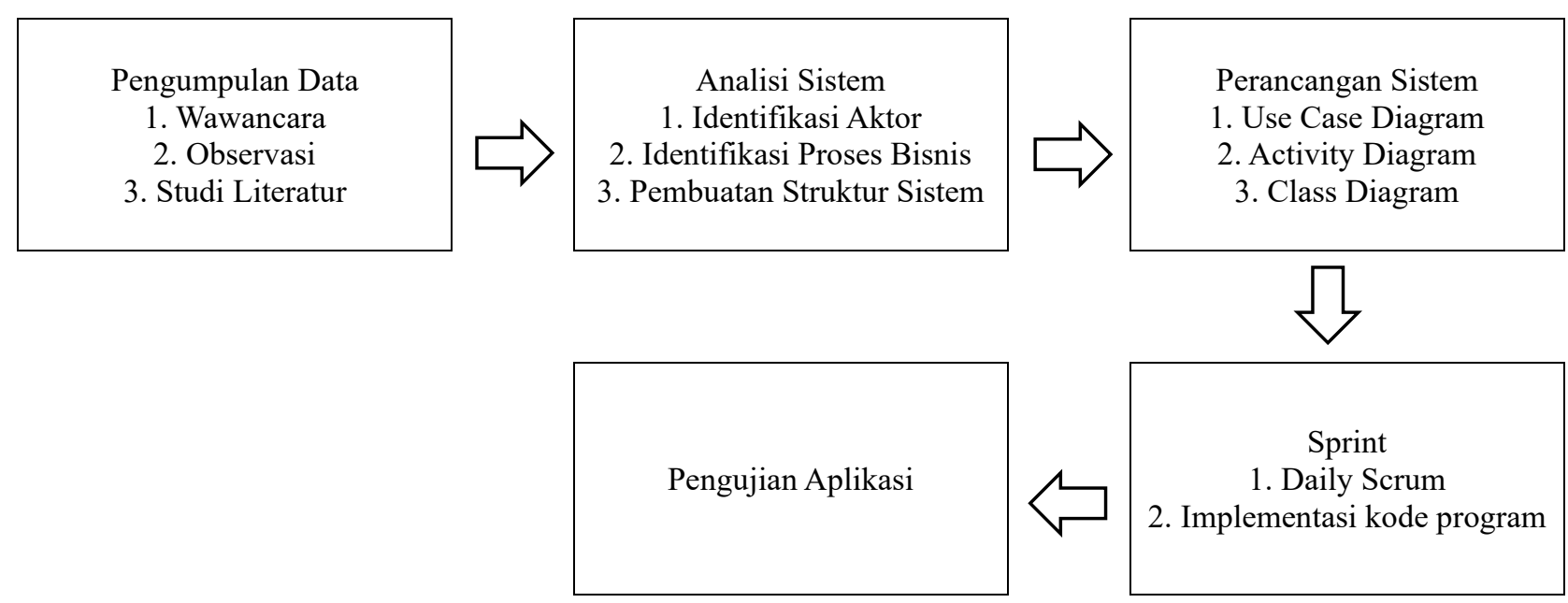

Gambar 1: Diagram Metodologi Penelitian

Pengumpulan data dilakukan dengan wawancara, observasi dan studi literature. Wawancara dilakukan kepada subag Teknologi Informasi di Badan Pusat Statistik Garut untuk memperoleh informasi mengenai aplikasi dan tujuan yang ingin dicapai dari aplikasi yang akan dibangun. Selanjutnya penulis melakukan observasi tentang aplikasi buku saku yang ada di internet sehingga memberikan informasi atau gambaran dalam membangun aplikasi. Kemudian studi litelatur dari berbagai sumber sebagai landasan penulis. Kemudian penulis akan menganalisa serta melakukan perancangan sistem menggunakan UML (Unified Modeling Language). Pengembangan sistem dilakukan dengan menggunakan metode scrum dengan tahapan yang ada hingga menghasilkan suatu aplikasi penjualan online yang utuh. Tahap terakhir penulis melakukan pengujian untuk memeriksa kinerja aplikasi.

Scrum adalah metodologi pengembangan tangkas yang digunakan dalam pengembangan Perangkat Lunak berdasarkan proses berulang dan inkremental. Scrum dapat disesuaikan, cepat, fleksibel dan efektif kerangka tangkas yang dirancang untuk memberikan nilai kepada pelanggan sepanjang pengembangan proyek. Tujuan utama scrum adalah untuk memenuhi kebutuhan pelanggan melalui lingkungan transparansi dalam komunikasi, tanggung jawab kolektif dan kemajuan berkelanjutan [5].

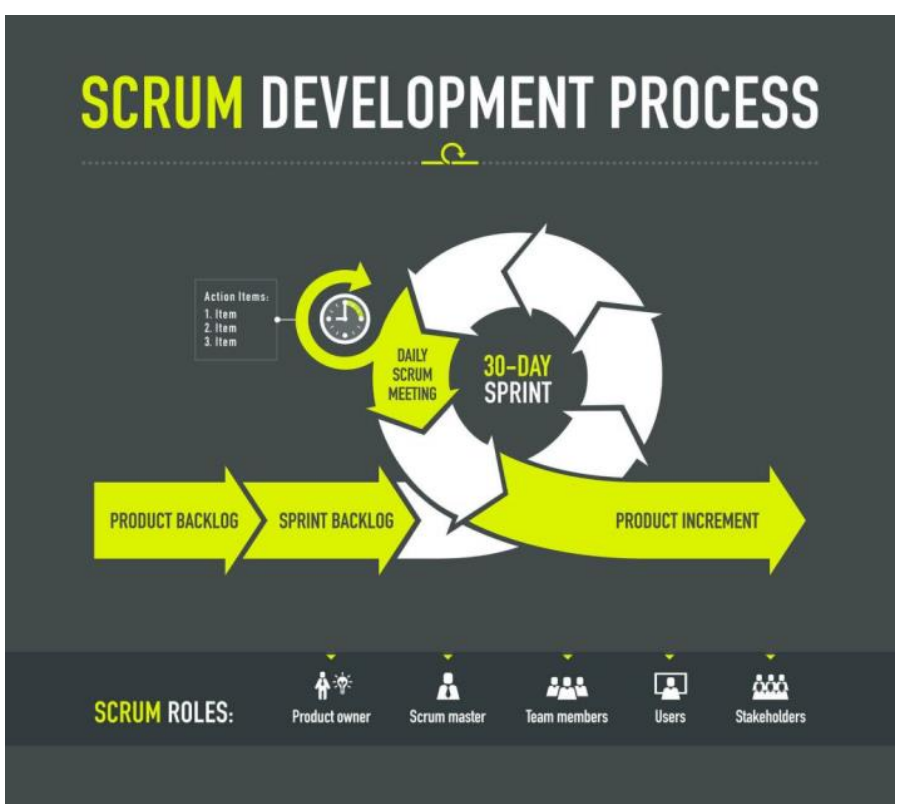

Gambar 2: Metodologi Agile Scrum 
Sprint adalah unit kerja dasar untuk tim Scrum. Ini adalah fitur utama yang menandai perbedaan antara Scrum dan model lain untuk pengembangan tangkas [6].

1. Sprint Planning adalah untuk menentukan apa yang akan dilakukan dalam Sprint dan bagaimana hal itu akan dilakukan. Pertemuan ini diadakan di awal setiap Sprint dan ditentukan bagaimana pendekatannya terhadap proyek yang berasal dari tahapan Product Backlog dan tenggat waktu.

2. Daily Scrum adalah untuk mengevaluasi kemajuan dan tren hingga akhir Sprint, menyelaraskan aktivitas dan membuat rencana untuk 24 jam ke depan. Ini adalah pertemuan singkat yang berlangsung setiap hari selama periode Sprint. Tiga pertanyaan dijawab satu per satu: Apa yang saya lakukan kemarin? Apa yang akan saya lakukan hari ini? Bantuan apa yang saya butuhkan? Scrum Master harus berusaha memecahkan masalah atau hambatan yang muncul.

3. Sprint Review adalah untuk menunjukkan pekerjaan apa yang telah diselesaikan sehubungan dengan jaminan simpanan produk untuk pengiriman di masa mendatang. Sprint yang sudah selesai ditinjau, dan harus sudah ada kemajuan yang jelas dan nyata dalam produk untuk disajikan kepada klien.

4. Sprint Retrospective yaitu tim meninjau tujuan yang telah diselesaikan dari sprint yang telah selesai, menuliskan yang baik dan yang buruk, agar tidak mengulangi kesalahan lagi. Tahap ini berfungsi untuk mengimplementasikan perbaikan dari sudut pandang proses pembangunan. Tujuan dari sprint retrospective adalah untuk mengidentifikasi kemungkinan perbaikan proses dan menghasilkan rencana untuk mengimplementasikannya di Sprint berikutnya.

\section{HASIL DAN PEMBAHASAN}

\section{A. Product Backlog}

Product Backlog adalah daftar yang muncul dan berurutan tentang apa yang diperlukan untuk meningkatkan produk. Ini adalah satu-satunya sumber pekerjaan yang dilakukan oleh Tim Scrum [7].

Tabel 1: Product Backlog

\begin{tabular}{|c|l|c|}
\hline No. & \multicolumn{1}{|c|}{ Item } & Prioritas \\
\hline 1. & Kebutuhan dokumen dan data Sedang \\
\hline 2. & Perancangan sistem dan basis data & Tinggi \\
\hline 3. & Struktur menu halaman utama & Sedang \\
\hline 4. & Menu profil & Sedang \\
\hline 5. & Menu Indikator Strategis & Tinggi \\
\hline 6. & Menu Jadwal Kegiatan & Sedang \\
\hline 7. & Menu master file desa & Sedang \\
\hline 8. & Menu Peta GIS & Tinggi \\
\hline
\end{tabular}

Pada product backlog yang terdapat di Tabel 1, aktivitas nomor 1 dan 2 ditujukan untuk mengidentifikasi dan merancang sistem informasi berdasarkan dokumen dan data yang telah dikumpulkan. Selanjutnya aktivitas nomor 3 dan seterusnya lebih berfokus pada pengembangan sistem berbasis android yang dalam pemrogramannya kebanyakan menggunakan bahasa Java.

Rancangan aplikasi menggunakan UML (Unified Modeling Language) yang merupakan salah satu teknik pemodelan desain sistem dengan menggunakan konsep OOP (Object Oriented Programming). Pemodelan ini menjadi bagian penting dalam pengembangan sistem karena menjadi satu satunya cara untuk memvisualisasikan desain sistem dan memeriksa apakah sudah memenuhi standar yang diinginkan sebelum memulai coding. Beberapa jenis UML yang dibuat antara lain yaitu Use Case Diagram, Activity Diagram, dan Class Diagram [8]. 
1. Use Case Diagram

Use case diagram dibuat untuk mengidentifikasi actor yang berperan dalam aplikasi buku saku BPS berbasis android [9].

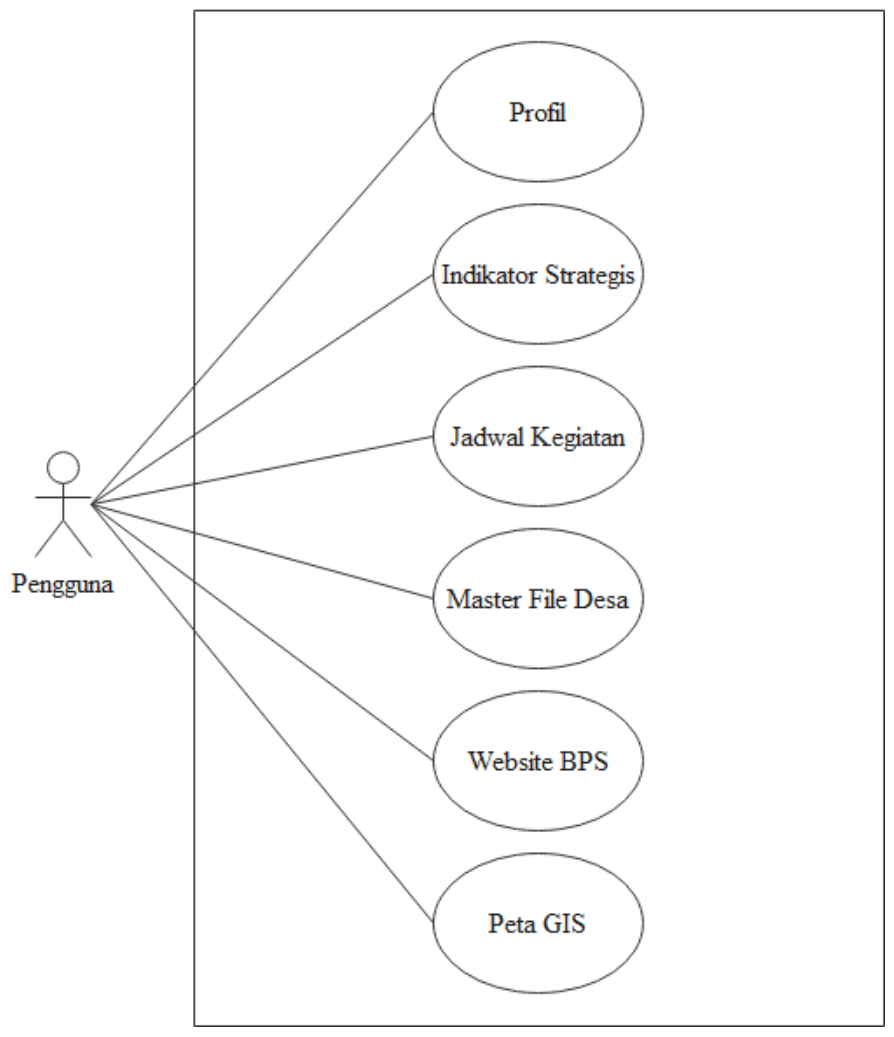

Gambar 3: Use Case Diagram

Berdasarkan gambar 3 pnegguna dapat mengakses halaman yang ada dalam aplikasi.

2. Activity Diagram

Setelah use case scenario telah digambarkan, maka selanjutnya adalah menggambarkan alur kerja dari use case scenario yang berupa activity diagram yang digunakan [10]. 


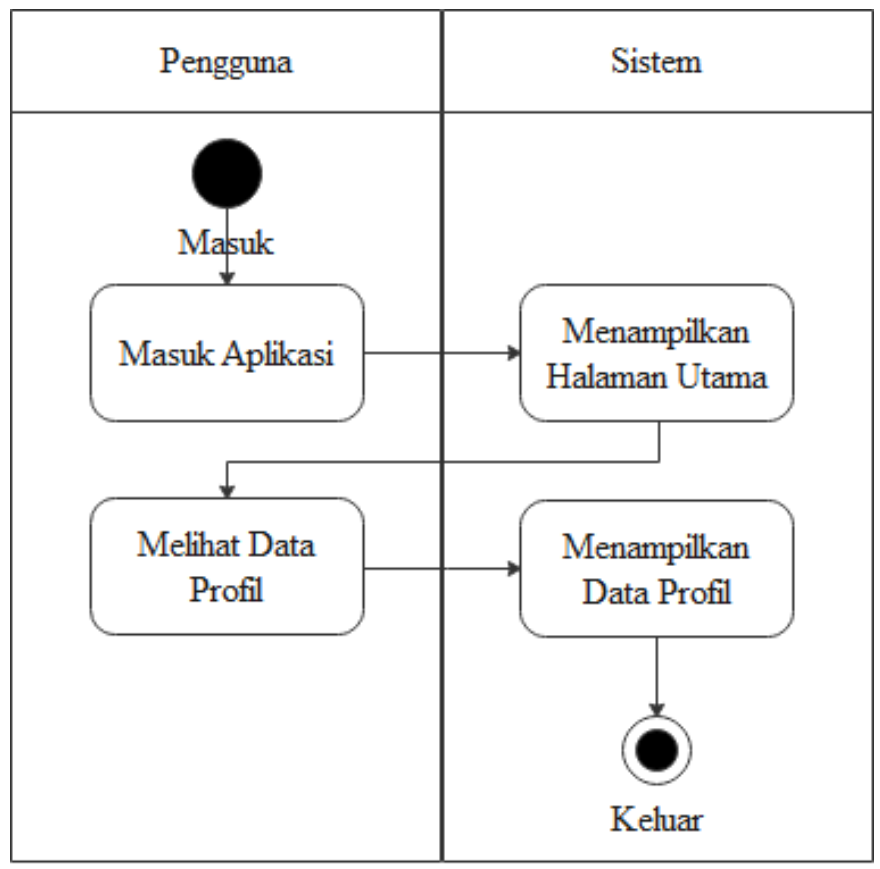

Gambar 4: Activity Diagram

Aktifitas yang sudah dilakukan Activity Diagram akan digunakan untuk mendapatkan gambaran mengenai alur dari aktifitas yang terdapat dalam penggunaan Buku Saku BPS seperti yang ditunjukkan pada gambar 4.

3. Class Diagram

Class diagram dalam Unified Modeling Language (UML) adalah jenis diagram struktur statis yang menggambarkan struktur sistem dengan menunjukkan kelas sistem, atributnya, operasi (atau metode), dan hubungan antar objek [11].

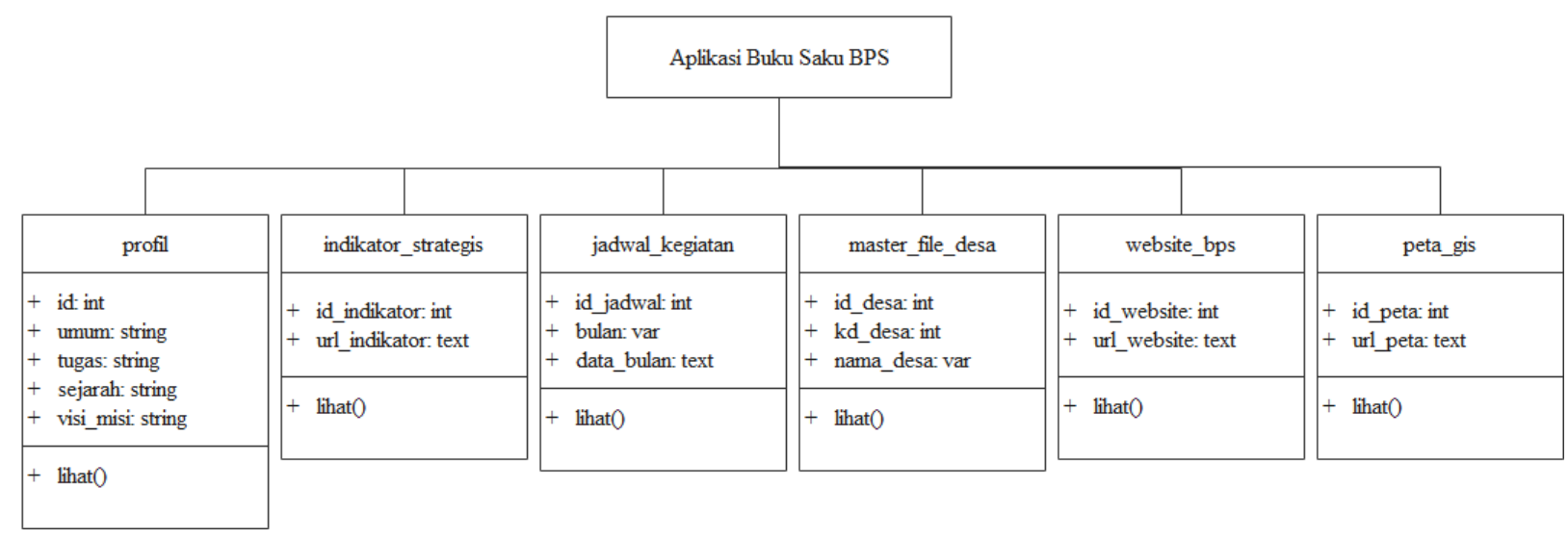

Gambar 5: Class Diagram

\section{B. Sprint}

Sprint adalah salah satu iterasi timeboxed dari siklus pengembangan berkelanjutan. Dalam Sprint, jumlah pekerjaan yang direncanakan harus diselesaikan oleh tim dan siap untuk ditinjau. Proyek scrum dipecah menjadi interval waktu kecil dan konsisten yang disebut sebagai sprint. Mereka bisa sesingkat beberapa hari dan umumnya tidak lebih dari $3-4$ minggu [12]. 
Tahap ini dibagi dalam 2 sesi yaitu sprint planning dan sprint backlog. Pada sprint planning, scrum team melakukan rapat untuk mengevaluasi daftar yang ada pada product backlog. Scrum team mendiskusikan setiap fitur yang nantinya akan dibangun oleh setiap anggota tim beserta estimasi waktu pengerjaannya seperti pada Tabel 2.

Tabel 2: Sprint Planning

\begin{tabular}{|c|l|c|}
\hline Aktor & \multicolumn{1}{|c|}{ Sprint Planning } & Estimasi Waktu \\
\hline \multirow{4}{*}{ Pengguna } & Halaman Utama & 3 Hari \\
\cline { 2 - 3 } & Menu profil & 3 Hari \\
\cline { 2 - 3 } & Menu Indikator Strategis & 3 Hari \\
\cline { 2 - 3 } & Menu Jadwal Kegiatan & 1 Hari \\
\cline { 2 - 3 } & Menu Master File Desa & 1 Hari \\
\cline { 2 - 3 } & Menu Peta GIS & 3 Hari \\
\hline
\end{tabular}

Selanjutnya pada sprint backlog, daftar fitur yang telah dibuat pada product backlog dan sprint planning dikumpulkan untuk dikerjakan oleh programmer seperti yang terlihat dalam Tabel 3. Setelah satu fitur dalam sprint planning selesai dikerjakan maka fitur lain akan dilanjutkan sprint berikutnya.

Tabel 3: Sprint Backlog 1 Menu profil

\begin{tabular}{|c|c|c|c|c|c|c|c|c|}
\hline \multirow{2}{*}{ Sprint } & \multirow{2}{*}{ Task } & \multicolumn{7}{|c|}{ Estimasi (Waktu/Jam) } \\
\hline & & 1 & 2 & 3 & 4 & 5 & 6 & 7 \\
\hline \multirow{4}{*}{ Menu profil } & Membuat tampilan & 3 & 2 & & & & & \\
\hline & Coding & & 7 & 3 & & & & \\
\hline & Testing & & 2 & 2 & & & & \\
\hline & Total & \multicolumn{7}{|c|}{ 24 Jam } \\
\hline
\end{tabular}

\section{Daily Scrum}

Daily scrum adalah acara 15 menit untuk Pengembang Tim Scrum. Untuk mengurangi kerumitan, diadakan pada waktu dan tempat yang sama setiap hari kerja Sprint. Jika Pemilik Produk atau Scrum Master secara aktif mengerjakan item di Sprint Backlog, mereka berpartisipasi sebagai Pengembang.

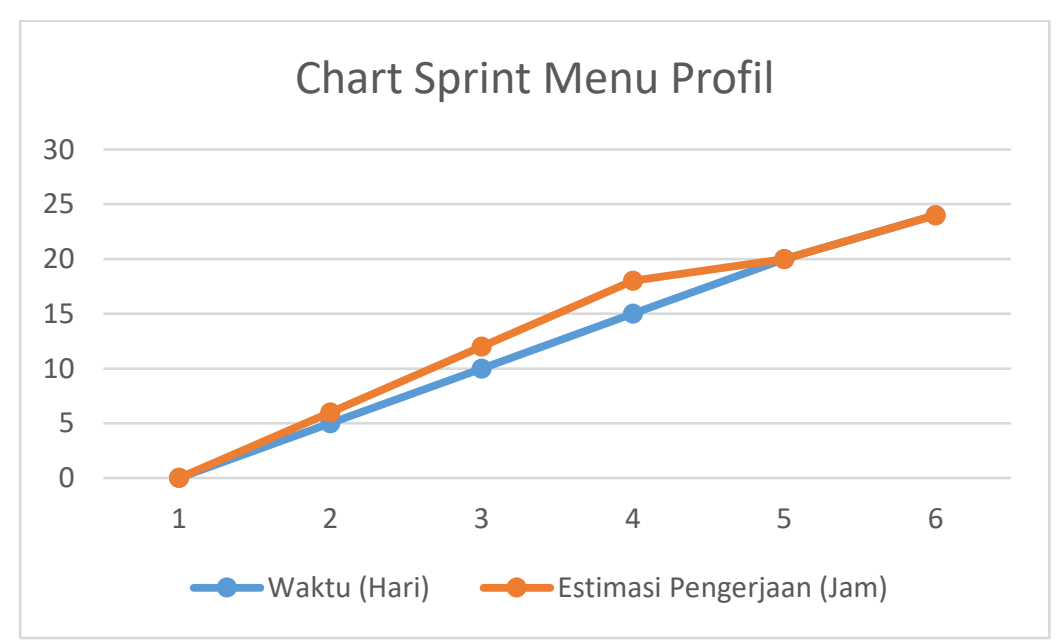

Gambar 6: Chart Sprint Menu Profil 1 


\section{Sprint Review}

Sprint review adalah pertemuan informal yang akan dihadiri oleh tim pengembangan, scrum master, pemilik produk, dan pemangku kepentingan. Tim memberikan demo pada produk dan akan menentukan apa yang selesai dan apa yang tidak. Tujuan pertemuan Sprint Review adalah agar tim menunjukkan kepada pelanggan dan pemangku kepentingan pekerjaan yang telah mereka capai selama sprint dan membandingkannya dengan komitmen yang diberikan di awal sprint.

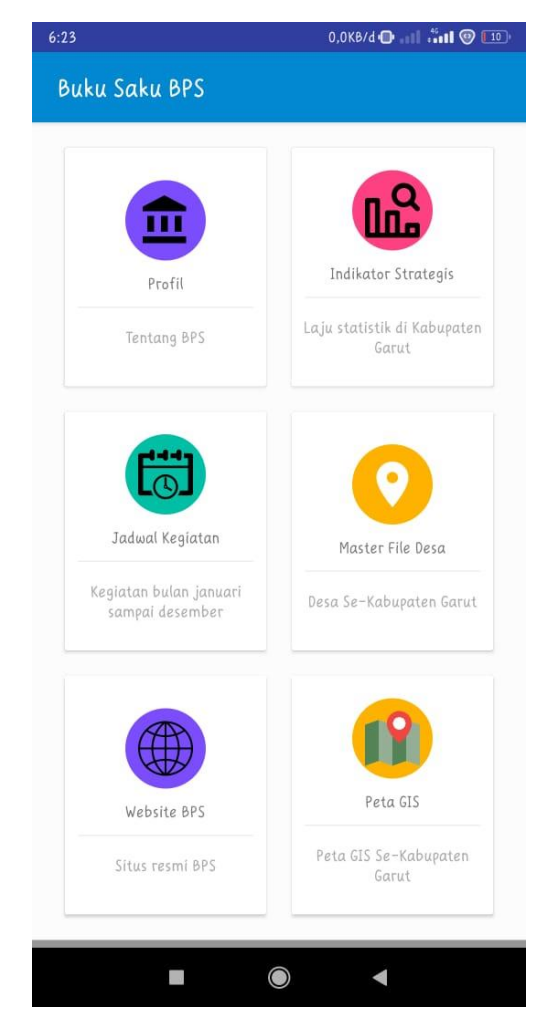

Gambar 7: Halaman Utama

\section{KESIMPULAN}

Kesimpulan penelitian ini menghasilkan aplikasi Buku Saku Badan Pusat Statistik Kabupaten Garut berbasis android. Pembuatan aplikasi berbasis android ini berhasil menyajikan buku saku dalam bentuk digital yang dapat di gunakan kapan saja. Selain itu, metode pengembangan sistem scrum juga membantu pembuat dalam menyesuaikan kebutuhan sistem. Dengan sumber daya yang terbatas, scrum mampu menyelesaikan aplikasi untuk mencapai tujuan dari setiap fitur-fitur yang dibutuhkan oleh pengguna dengain baik.

\section{DAFTAR PUSTAKA}

[1] A. Malik, H. Aulawi, and R. Setiawan, "Sistem Informasi Potensi Investasi Terintegrasi Menggunakan Scrum Agile,” J. Algoritm., 2020, doi: 10.33364/algoritma/v.16-2.108.

[2] D. D. S. Fatimah, E. Satria, and A. Andriyani, "Rancang Bangun Aplikasi Media Interaktif Fiqih Pengurusan Jenazah Berbasis Android," J. Algoritm., 2020, doi: 10.33364/algoritma/v.16-2.181.

[3] Z. Fang, "e-Goverment in digital era : concept, practice and development," Int. J. Comput. Internet Manag., 2002.

[4] S. Sapri and R. T. Alinse, "Rancang Bangun Sistem Informasi Koperasi Karyawan Pada Badan Pusat 
Statistik (BPS) Kota Bengkulu," Pseudocode, 2019, doi: 10.33369/pseudocode.6.1.30-38.

[5] Digite, "What is Scrum?," Digite. https://www.digite.com/agile/scrum-methodology/.

[6] A. Wahyudi, "Analisis Pengembangan Perpustakaan Digital Bebasis Android Dengan Metode Scrum," Fakt. Exacta, 2018, doi: 10.30998/faktorexacta.v11i2.2484.

[7] scrum.org, "What is a Product Backlog?," scrum.org. https://www.scrum.org/resources/what-is-aproduct-backlog.

[8] D. D. S. Fatimah, R. Kurniawati, I. Farida, and Y. Pariyatin, "Website for remote village empowerment in developing countries," J. Phys. Conf. Ser., vol. 1402, no. 7, 2019, doi: 10.1088/1742-6596/1402/7/077009.

[9] K. C. Dewi, P. I. Ciptayani, and I. W. R. Wijaya, "Agile Project Management Pada Pengembangan EMusrenbang Kelurahan Benoa Bali Agile Project Management On E-Musrenbang Development In Benoa Village Bali,” J. Teknol. Inf. dan Ilmu Komput., 2018.

[10] A. Mukhtarif, B. T. Hanggara, and K. C. Brata, "Pengembangan Sistem Informasi Buku Saku Karakter Berbasis Android ( Studi Kasus : SD UMP Purwokerto ),” vol. 4, no. 11, pp. 3921-3930, 2020.

[11] U. F. Amin Farozi, "Buku saku gerakan pramuka bilingual berbasis android 1," KomuniTi, vol. VI, no. 2, pp. 162-171, 2014.

[12] F. M. Fowler, "What Is Scrum?," in Navigating Hybrid Scrum Environments, 2019. 